\title{
Choroidal thickness in relation to urinary albumin excretion rate in type 2 diabetes mellitus without retinopathy
}

\author{
Doaa Maamoun Ashour ${ }^{*}$ (10, Amany Abd El-Fattah El-Shazly ${ }^{\circledR 0}$, Randa Hesham Ali Abdelgawad and \\ Mohamed Ibrahim Saleh (1)
}

\begin{abstract}
Background: To evaluate choroidal thickness (CT) in diabetic patients without diabetic retinopathy (DR) in relation to the urinary albumin excretion rate (UAER).

Methods: This is a prospective case-control study that included a consecutive sample of 120 patients with type 2 diabetes without clinically evident DR and a group of 60 matched healthy controls. Diabetic patients were included in two groups according to their UAER (normoalbuminuria and microalbuminuria). Complete ophthalmological examination was performed followed by optical coherence tomography (SD-OCT) for retinal and choroidal assessment. Twenty-four-hour urine samples were collected for UAER and blood samples for $\mathrm{HbA1c}$ and serum creatinine were obtained.

Results: The study included 180 eyes from 180 subjects in three groups. Patients with higher levels of albuminuria had a thinner choroid than normal controls, with decremental thinning as albuminuria progressed. Diabetics with normoalbuminuria showed no significant differences from controls. Choroidal thickness showed a significant moderate negative correlation with UAER $(r=-0.58, p<0.001)$. Multiple regression analyses for diabetic patients with microalbuminuria demonstrated that UAER is the most important determinant of subfoveal choroidal thickness (SFCT) $(p<0.001)$.
\end{abstract}

Conclusions: Decreased CT was significantly correlated with UAER in diabetic patients without retinopathy and otherwise normal kidney functions. This decrease in thickness might be a predictor of DR.

Keywords: Choroidal thickness, Diabetic retinopathy, Microalbuminuria, Urinary albumin excretion rate

\section{Introduction}

Diabetes is one of the greatest health problems worldwide, with an estimated global prevalence of 9.3\% (463 million people) in 2019, with an expected increase to $10.9 \%$ (700 million) by 2045 [1]. More than $90 \%$ of diabetic patients suffer from type 2 diabetes mellitus (DM), which is a known cause of various microvascular and

*Correspondence: drdoaa_ashour@med.asu.edu.eg Ophthalmology Department, Faculty of Medicine, Ain Shams University, Cairo, Egypt macrovascular complications that can significantly affect patient life [2]. Diabetic retinopathy (DR) is one of the complications that affects more than $35 \%$ of diabetic patients and is considered the leading cause of visual loss in working-age adults [3]. Thus, screening programs for early detection of DR have been widely adopted. However, with variable socioeconomic levels in different areas many diabetic patients are not undergoing regular screening until they present with late complications [4].

Various studies were conducted aiming to identify early predictors of DR progression [5]. One of the identified original author(s) and the source, provide a link to the Creative Commons licence, and indicate if changes were made. The images or other third party material in this article are included in the article's Creative Commons licence, unless indicated otherwise in a credit line to the material. If material is not included in the article's Creative Commons licence and your intended use is not permitted by statutory regulation or exceeds the permitted use, you will need to obtain permission directly from the copyright holder. To view a copy of this licence, visit http://creativecommons.org/licenses/by/4.0/. The Creative Commons Public Domain Dedication waiver (http://creativeco mmons.org/publicdomain/zero/1.0/) applies to the data made available in this article, unless otherwise stated in a credit line to the data. 
prognostic factors is microalbuminuria, which was identified as an early marker of generalized endothelial damage associated with chronic microvascular complications of diabetes [6]. Yearly, $5-10 \%$ of type 2 DM with microalbuminuria develop diabetic nephropathy, which is also associated with an increased risk of developing DR [7].

Previous clinical and histopathological studies have shown that vascular dysfunction in DM may affect both the choroidal and retinal vasculature. Several choroidal abnormalities have been reported in the eyes of diabetic patients including increased vascular tortuosity, obstruction of the choriocapillaris, and areas of non-perfusion or neovascularization [8-11].

With the continuous advancements in imaging techniques, detailed choroidal observation and measurements have become possible via new generations of optical coherence tomography (OCT) systems including enhanced depth imaging (EDI) mode in spectral-domain (SD-OCT), swept-source OCT, en face OCT, and optical coherence tomography angiography [12]. Using these machines, many studies have shown a significant difference in choroidal thickness (CT) of diabetic eyes compared to healthy eyes [13-16]. However, the findings of these studies were mostly controversial and inconsistent, especially in patients without DR [17-19].

Identification of an early predictor for DR via simple non-invasive imaging will be of utmost importance and will save many eyes. Knowing that microalbuminuria was previously identified as the earliest sign of diabetic nephropathy and an early predictor for DR, we conducted this research to study CT changes in the eyes of diabetic patients before evident diabetic changes and to compare these changes with the patients' urinary albumin excretion rate (UAER). Aiming to identify the possibility of using choroidal thickness changes as an early predictor of DR.

\section{Methods}

This is a prospective case-control study. The study protocol was approved by the Research Ethics committee of the Faculty of Medicine, Ain Shams University. The study strictly adhered to research ethics as stated in the Declaration of Helsinki.

Patients were recruited from the outpatient clinic at Ain Shams University Hospital, Cairo, Egypt. Diabetic patients who met the inclusion criteria were invited to participate $(n=120)$. A group of healthy controls was included $(n=60)$. Written informed consent was obtained from all participants.

Inclusion criteria included being diagnosed with type $2 \mathrm{DM}$ for more than 5 years without any evidence of DR on dilated fundus examination. Exclusion criteria included a refractive error of more than \pm 3 diopters (D), pre-existing retinal diseases, uveitis, glaucoma, media opacities, previous ocular trauma, or any ocular surgery. Patients with axial length (AL) longer than $25 \mathrm{~mm}$ were excluded due to the previously identified negative correlation between AL and CT [20]. Patients were also excluded if they were smokers or having uncontrolled systemic hypertension (150/95 mm Hg) [19], systemic lupus erythematosus, anemia, leukemia, obstructive sleep apnea, or any neurodegenerative disease. Patients with albuminuria more than $300 \mathrm{mg} /$ day and/or elevated serum creatinine, Blood Urea Nitrogen, or decreased estimated glomerular filtration (eGFR) rate in their records were excluded from this study.

Study participants were divided into three groups: the control group (group 1) included 60 healthy participants who were age and sex-matched to the patients. The recruited diabetic patients were subdivided into two groups according to their UAER as measured in sterile 24-h timed urine samples by immunoturbidimetry (Microlab; Ames, Tarrytown, NY). Normoalbuminuria was defined as UAER less than $30 \mathrm{mg} /$ day, and microalbuminuria as UAER $30-300 \mathrm{mg} /$ day [21]. Diabetic patients with normoalbuminuria were assigned to group 2. Group 3 included patients with microalbuminuria.

All participants underwent a careful history taking, review of their annual systemic work-up including their laboratory investigations, complete ophthalmic examination, including best-corrected visual acuity (BCVA), anterior segment examination, intraocular pressure (IOP), and dilated fundus examination. Retinal and choroidal imaging were performed using SD-OCT, Nidek RS-3000 Advance (Nidek, Gamagori, Japan). Finally, axial length (AL) was obtained (PacScan 300A; Sonomed Escalon Inc, New York, NY).

Blood samples were obtained for random blood sugar (RBS), serum creatinine, and HbA1c measurements. Estimated glomerular filtration rate (eGFR) was calculated using the Modification of Diet in Renal Disease (MDRD) formula [22].

Optical coherence tomography was performed after mydriasis using tropicamide $0.5 \%$ tropicamide eye drops (Mydriacyl 0.5\%; Alcon Inc). Images were taken between 10 am and $12 \mathrm{pm}$ to avoid diurnal variations [23]. Macular map was obtained, followed by choroidal imaging via the enhanced depth technique by approaching the OCT device closer to the eye until an inverted image with clear choroidal details and good signal strength was obtained. Macula 12 radial scans were obtained, and the sclerochoroidal interface was manually outlined in each scan. Image capture and manual editing were conducted by the same experienced OCT operator who was blinded from the diagnosis of the patients. All scans were revised for signal strength, centration, and accurate choroidal 
outlines between the outer boundaries of the retinal pigment epithelium and the sclero-choroidal interface prior to inclusion. Finally, a choroidal thickness map was generated by the incorporated software using the ETDRS chart including subfoveal choroidal thickness (SFCT) in the innermost $1 \mathrm{~mm}$ circle, inner $3 \mathrm{~mm}$ circle, and outer $6 \mathrm{~mm}$ circle. The $3 \mathrm{~mm}$ and $6 \mathrm{~mm}$ circles were divided into superior, inferior, nasal, and temporal quadrants.

Axial length measurements were obtained after previous noncontact imaging using A-scan after topical corneal anesthesia ( $0.4 \%$ benoxinate $\mathrm{HCl}$ eye drops). Five axial length $(\mathrm{AL})$ measurements were obtained to calculate the average value.

\section{Statistical analysis}

For data analysis, the Statistical Package for Social Sciences version 15.0 (SPSS $\odot$ v. 15.0, SPSS Inc., Chicago, IL, USA) was used. Quantitative data were presented as mean \pm standard deviation (SD). Gender differences were done using the Chi-square test. Multiple groups mean of parametric data sets were compared using a oneway analysis of variance (ANOVA) test. Further analysis with Tukey's honestly significant difference (HSD) posthoc test if an overall significance was found. Pearson's correlation and regression analyses were done to evaluate the different factors that influence choroidal thickness. $\mathrm{p}$ values $<0.05$ were considered statistically significant.

\section{Results}

\section{Baseline characteristics}

In this study, a total of 180 eyes (one eye from each patient randomly selected) of 180 subjects were included.
Sixty in each group. The age ranged from 40 to 63 years. They were 85 males and 95 females without a statistically significant difference between the various groups. Male/ female ratio was $26 / 34$ in group $1,28 / 32$ in group 2 , and $31 / 29$ in group $3\left(x^{2}=0.87\right.$ and $\left.p=0.833\right)$.

Slit-lamp and fundus examinations did not reveal abnormalities in all patients. There were no significant differences between the three groups in age, IOP, BCVA, and spherical equivalent (SE) as determined using oneway ANOVA (Table 1). All the included subjects had normal serum creatinine and eGFR with no statistically significant difference between the study groups (Table 1). One-way ANOVA showed that HbA1c and UAER were higher in diabetics than in controls. Post hoc test revealed that the HbA1c and UAER were statistically significantly lower in group 1 than in group 2, and both were lower in group 2 than in group 3. (Table 1).

\section{Choroidal thickness}

One-way ANOVA revealed that CT was significantly thinner in diabetic patients compared to control subjects in 9 locations (Table 2). Post hoc (Tukey's HSD) showed that CT showed insignificant differences between the normoalbuminuric patients and the controls in the 9 sectors, while, in the nine sectors, the CT of group 3 was statistically lower than those of groups 1 and 2. (Table 2).

We compared SFCT in group 3 to the patients' age, duration of DM, HbA1c, RBS, UAER, serum creatinine, eGFR, IOP, SE, and AL. In diabetic patients with microalbuminuria (Group 3), SFCT showed only a significant negative correlation with UAER $(\mathrm{r}=-0.58$ and $\mathrm{p}<$ 0.001). (Table 3; Fig. 1).

Table 1 Clinical and demographic characteristics of the studied groups

\begin{tabular}{|c|c|c|c|c|c|c|c|c|}
\hline & \multirow{2}{*}{$\begin{array}{l}\text { Group } 1 \\
\text { Mean } \pm \text { SD }\end{array}$} & \multirow{2}{*}{$\begin{array}{l}\text { Group } 2 \\
\text { Mean } \pm \text { SD }\end{array}$} & \multirow{2}{*}{$\begin{array}{l}\text { Group } 3 \\
\text { Mean } \pm \text { SD }\end{array}$} & \multirow[t]{2}{*}{$\mathrm{F}$} & \multirow[t]{2}{*}{$p$} & \multicolumn{3}{|c|}{ Post hoc test } \\
\hline & & & & & & 1 vs 2 & 1 vs 3 & 2 vs 3 \\
\hline Age (years) & $47.31 \pm 4.71$ & $48.45 \pm 4.75$ & $48.98 \pm 4.99$ & 1.87 & 0.157 & 0.404 & 0.143 & 0.817 \\
\hline Duration of DM (years) & - & $7.96 \pm 2.16$ & $8.42 \pm 2.35$ & 1.29 & 0.259 & - & - & 0.259 \\
\hline HBA1C (\%) & $5.75 \pm 0.42$ & $8.08 \pm 0.88$ & $11.53 \pm 1.20$ & 637.14 & $<0.001$ & $<0.001$ & $<0.001$ & $<0.001$ \\
\hline RBS (mg/dl) & $182.93 \pm 28.12$ & $225.85 \pm 37.00$ & $309.70 \pm 48.23$ & 166.79 & $<0.001$ & $<0.001$ & $<0.001$ & $<0.001$ \\
\hline BCVA (LogMAR) & $0.00 \pm 0.00$ & $0.00 \pm 0.00$ & $0.00 \pm 0.00$ & - & - & 1.000 & 1.000 & 1.000 \\
\hline IOP $(\mathrm{mm} \mathrm{Hg})$ & $13.85 \pm 1.62$ & $13.43 \pm 1.42$ & $13.75 \pm 1.63$ & 1.03 & 0.358 & 0.326 & 0.702 & 0.803 \\
\hline SE (D) & $-0.26 \pm 0.52$ & $-0.30 \pm 0.39$ & $-0.35 \pm 0.39$ & 0.65 & 0.523 & 0.862 & 0.490 & 0.809 \\
\hline $\mathrm{AL}(\mathrm{mm})$ & $23.82 \pm 0.70$ & $23.96 \pm 0.66$ & $23.98 \pm 0.51$ & 1.07 & 0.344 & 0.470 & 0.372 & 0.984 \\
\hline UAER ( $\mu \mathrm{g} / \mathrm{min})$ & $11.94 \pm 2.71$ & $13.89 \pm 42.08$ & $115.71 \pm 42.08$ & 352.35 & $<0.001$ & 0.915 & $<0.001$ & $<0.001$ \\
\hline Serum creatinine (mg/dL) & $0.78 \pm 0.12$ & $0.79 \pm 0.10$ & $0.77 \pm 0.11$ & 0.49 & 0.612 & 0.873 & 0.873 & 0.582 \\
\hline $\begin{array}{l}\text { eGFR } \\
\left(\mathrm{mL} / \mathrm{min} / 1.73 \mathrm{~m}^{2}\right)\end{array}$ & $100.78 \pm 5.83$ & $99.82 \pm 5.16$ & $100.47 \pm 5.31$ & 0.48 & 0.616 & 0.599 & 0.948 & 0.790 \\
\hline
\end{tabular}

HBA1c glycosylated haemoglobin; RBS random blood sugar; CCT central corneal thickness; $B C V A$ best corrected visual acuity; IOP intraocular pressure; $S E$ spherical equivalent; $A L$ axial length; UAER urinary albumin excretion rate; eGFR estimated glomerular filtration rate calculated using the MDRD (modification of diet in renal disease) formula 
Table 2 Choroidal thickness (CT) of the studied groups

\begin{tabular}{|c|c|c|c|c|c|c|c|c|}
\hline \multirow[t]{2}{*}{ Variable $(\mu \mathrm{m})$} & \multirow{2}{*}{$\begin{array}{l}\text { Group } 1 \\
\text { Mean } \pm \text { SD }\end{array}$} & \multirow{2}{*}{$\begin{array}{l}\text { Group } 2 \\
\text { Mean } \pm \text { SD }\end{array}$} & \multirow{2}{*}{$\begin{array}{l}\text { Group } 3 \\
\text { Mean } \pm \text { SD }\end{array}$} & \multirow[t]{2}{*}{$F$} & \multirow[t]{2}{*}{$\mathbf{P}$} & \multicolumn{3}{|c|}{ Post hoc test } \\
\hline & & & & & & 1 vs 2 & 1 vs 3 & 2 vs 3 \\
\hline SFCT & $293.48 \pm 28.51$ & $285.87 \pm 20.30$ & $270.82 \pm 14.90$ & 16.55 & $<0.001$ & 0.141 & $<0.001$ & $<0.001$ \\
\hline SIM & $285.48 \pm 26.08$ & $278.88 \pm 21.51$ & $266.62 \pm 22.41$ & 10.03 & $<0.001$ & 0.273 & $<0.001$ & 0.013 \\
\hline$\| \mathrm{M}$ & $287.47 \pm 36.19$ & $279.02 \pm 24.93$ & $261.67 \pm 36.36$ & 9.86 & $<0.001$ & 0.218 & $<0.001$ & 0.019 \\
\hline TIM & $277.03 \pm 28.48$ & $273.72 \pm 35.27$ & $259.10 \pm 22.83$ & 6.36 & 0.002 & 0.809 & 0.003 & 0.019 \\
\hline NIM & $280.27 \pm 21.96$ & $275.88 \pm 31.45$ & $261.27 \pm 25.38$ & 8.42 & $<0.001$ & 0.638 & $<0.001$ & 0.008 \\
\hline SOM & $268.85 \pm 19.00$ & $263.48 \pm 18.55$ & $250.20 \pm 23.10$ & 13.40 & $<0.001$ & 0.319 & $<0.001$ & 0.001 \\
\hline IOM & $270.32 \pm 16.88$ & $266.32 \pm 14.67$ & $254.90 \pm 22.54$ & 11.43 & $<0.001$ & 0.458 & $<0.001$ & 0.002 \\
\hline TOM & $272.65 \pm 23.94$ & $265.10 \pm 21.35$ & $251.12 \pm 18.05$ & 15.86 & $<0.001$ & 0.129 & $<0.001$ & 0.001 \\
\hline NOM & $270.87 \pm 21.29$ & $267.33 \pm 20.82$ & $255.68 \pm 22.07$ & 8.27 & $<0.001$ & 0.638 & $<0.001$ & 0.009 \\
\hline
\end{tabular}

SFCT subfoveal choroidal thickness; SIM superior of the inner macula (CT); IIM inferior of the inner macula (CT); TIM temporal of the inner macula (CT); NIM nasal of the inner macula (CT); SOM superior of the outer macula (CT); IOM inferior of outer macula (CT); TOM temporal of the outer macula (CT); NOM nasal of the outer macula (CT)

Table 3 Correlations between subfoveal choroidal thickness (SFCT) and different parameters in the microalbuminuric group

\begin{tabular}{llr}
\hline & \multicolumn{2}{c}{ SFCT in microalbuminuric } \\
& patients (Group 3) \\
\cline { 2 - 3 } & $\mathbf{r}$ & $\mathbf{p}$ \\
\hline Age (years) & -0.08 & 0.543 \\
Duration of DM (years) & -0.20 & 0.125 \\
HBA1c\% & -0.23 & 0.077 \\
RBS (mg/dl) & -0.07 & 0.595 \\
IOP (mm Hg) & -0.24 & 0.065 \\
SE (D) & -0.05 & 0.704 \\
AL (mm) & -0.09 & 0.494 \\
UAER ( $\mu \mathrm{gg} / \mathrm{min})$ & -0.58 & $<0.001$ \\
Serum creatinine $(\mathrm{mg} / \mathrm{dL})$ & 0.08 & 0.543 \\
eGFR (mL/min/1.73 m²) & -0.01 & 0.940
\end{tabular}

HBA1C glycosylated hemoglobin; RBS random blood sugar; $C C T$ central corneal thickness; IOP intraocular pressure; SE spherical equivalent; $A L$ axial length; UAER urinary albumin excretion rate; GFR estimated glomerular filtration rate

Also, CT in the 3 - and 6-mm rings (8 sectors) in microalbuminuric patients (Group 3) showed a significant negative correlation with UAER (Table 4).

In multiple regression analyses, UAER was found to be the most important determinant of SFCT in patients with microalbuminuria (Table 5).

\section{Discussion}

In the current study, we used SD-OCT to assess CT in diabetic patients with and without albuminuria in the absence of retinopathy. Although SS-OCT might be a preferred imaging modality for choroidal visualization owing to better penetration of deeper tissues by the longer wavelength sweeping laser [24]. However, with the more availability of SD-OCT as well as its ability to clearly visualize the sclerochoroidal interface using EDI (93\% of 3468 subjects) as found by Wei et al. [25], SDOCT was used in the current study. Failure of visualization is usually related to inadequate light penetration as in cases of media opacity [24]. Thus, all cases with media opacity or poor-quality OCT were excluded from this study. The same technique for choroidal thickness measurement was applied to a control group for standardized comparison.

The mean value of $\mathrm{CT}$ in diabetic patients with microalbuminuria was significantly lower compared to controls in the 9 ETDRS sectors. A decremental pattern of the CT of the nine locations was noticed, being the lowest for microalbuminuric ones (Group 3).

The relationship between DR and UAER was previously studied. Microalbuminuria was found as a predictor of DR. Moreover, greater prevalence of DR and more severity were reported in patients with macroalbuminuria than in those with microalbuminuria [21, 26]. While there is limited research on the relation between CT in diabetic patients and UAER. To the best of our knowledge, this relation was studied twice before. Like our results, Farias et al. found that choroidal changes were present in type 2 diabetic patients (37 patients) before the clinical development of retinopathy. Microalbuminuria was significantly correlated with a reduction in choroidal thickness and volume in diabetic patients without retinopathy [28]. On the contrary, Oliveira-Ferreira et al. [18] in their retrospective study stated that the SFCT was higher in diabetic patients without DR when compared to nondiabetic patients. Microalbuminuria was accompanied by thickening of the subfoveal and temporal choroid in diabetic patients without DR when compared with normoalbuminuric diabetics and non-diabetics [18]. 


\section{UAER of mic roalbuminuric group $=\mathbf{5 5 6 . 6 7}-\mathbf{1 . 6 2 8}$ \\ * SFCT of microalbuminuric group Correlation: $r=-\mathbf{0 . 5 8} \quad \mathrm{p}<\mathbf{0 . 0 0 1}$}

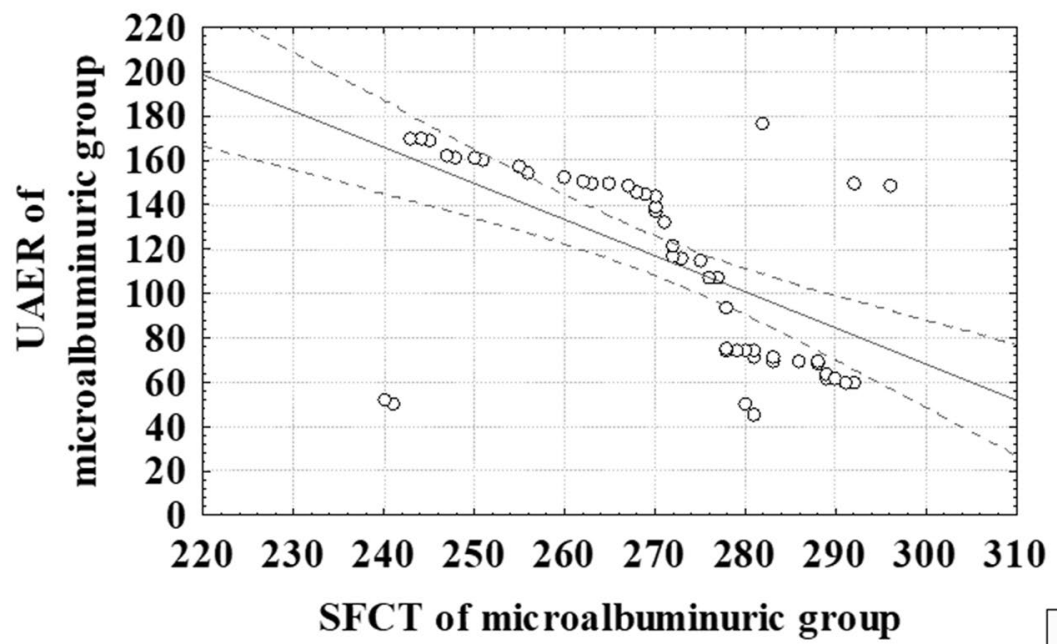

\section{a $95 \%$ confidence}

Fig. 1 Correlation between subfoveal choroidal thickness in the innermost $1 \mathrm{~mm}$ circle and urinary albumin excretion rate in diabetic patients with microalbuminuria (Group 3). SFCT subfoveal choroidal thickness; UAER urinary albumin excretion rate

Table 4 Correlations between $\mathrm{HBA} 1 \mathrm{C} \%$ and urinary albumin excretion ratio (UAER) with the choroidal thickness $(\mathrm{CT})$ in different sectors in the microalbuminuric diabetic patients

\begin{tabular}{|c|c|c|c|c|}
\hline \multirow[t]{3}{*}{ Variable $(\mu \mathrm{m})$} & \multicolumn{4}{|c|}{ Microalbuminuric group } \\
\hline & \multicolumn{2}{|c|}{ HBA1C\% } & \multicolumn{2}{|c|}{ UAER ( $\mu \mathrm{g} / \mathrm{min})$} \\
\hline & $r$ & $p$ & $r$ & $p$ \\
\hline SFCT & -0.23 & 0.077 & -0.58 & $<0.001$ \\
\hline SIM & -0.18 & 0.169 & -0.69 & $<0.001$ \\
\hline$\| M$ & -0.04 & 0.762 & -0.55 & $<0.001$ \\
\hline TIM & -0.08 & 0.649 & -0.60 & $<0.001$ \\
\hline NIM & -0.15 & 0.146 & -0.65 & $<0.001$ \\
\hline SOM & 0.02 & 0.704 & -0.39 & 0.002 \\
\hline IOM & -0.07 & 0.879 & -0.35 & 0.006 \\
\hline TOM & -0.15 & 0.253 & -0.56 & $<0.001$ \\
\hline NOM & -0.06 & 0.649 & -0.53 & $<0.001$ \\
\hline
\end{tabular}

SFCT subfoveal choroidal thickness; SIM superior of the inner macula (CT); IIM inferior of the inner macula (CT); TIM temporal of the inner macula (CT); NIM nasal of the inner macula (CT); SOM superior of the outer macula (CT); IOM inferior of outer macula (CT); TOM temporal of the outer macula (CT); NOM nasal of the outer macula (CT)

These controversial results might be attributed to the manual measurement of $\mathrm{CT}$ in specified points rather than obtaining a map. Additionally, the effect of circadian rhythm may be a contributing factor. Both studies have not included the renal function tests of the patients. The
Table 5 Multiple regression analysis of different factors affecting subfoveal choroidal thickness (SFCT) in microalbuminuric patients

\begin{tabular}{|c|c|c|c|c|}
\hline & \multicolumn{4}{|c|}{ Microalbuminuric patients } \\
\hline & $\beta$ & B & $t$ & $p$ value \\
\hline Intercept & & 156.65 & 1.42 & 0.161 \\
\hline Age (years) & 0.01 & 0.03 & 0.09 & 0.926 \\
\hline Duration of DM (years) & 0.12 & 0.75 & 1.03 & 0.308 \\
\hline HBA1C\% & -0.16 & -1.93 & -1.32 & 0.193 \\
\hline $\mathrm{RBS}(\mathrm{mg} / \mathrm{dl})$ & 0.11 & 0.03 & 0.93 & 0.357 \\
\hline IOP $(\mathrm{mm} \mathrm{Hg})$ & 0.17 & 1.99 & 1.48 & 0.146 \\
\hline SE (D) & -0.06 & -2.41 & -0.54 & 0.589 \\
\hline $\mathrm{AL}(\mathrm{mm})$ & 0.02 & 0.67 & 0.20 & 0.845 \\
\hline $\operatorname{UAER}(\mu \mathrm{g} / \mathrm{min})$ & -0.48 & -0.17 & -3.96 & $<0.001$ \\
\hline Creatinine $(\mathrm{mg} / \mathrm{dL})$ & 0.16 & 21.86 & 1.54 & 0.1309 \\
\hline $\operatorname{eGFR}\left(\mathrm{mL} / \mathrm{min} / 1.73 \mathrm{~m}^{2}\right)$ & -0.04 & -0.12 & -0.40 & 0.693 \\
\hline
\end{tabular}

Regression summary for SFCT of diabetic patients with microalbuminuria $\mathrm{R}=$ $0.641 ; R^{2}=0.411 ;$ Adjusted $R^{2}=0.0 .306 \mathrm{~F}(9.50)=3.884 \mathrm{p}$

$H B A 1$ c glycosylated hemoglobin; $R B S$ random blood sugar; $C C T$ central corneal thickness; IOP intraocular pressure; SE spherical equivalent; $A L$ axial length; UAER urinary albumin excretion rate; eGFR estimated glomerular filtration rate

included sample in the current study had normal serum creatine and eGFR thus none had chronic diabetic kidney disease [27]. The current study was designed to allow matched characteristics between the study groups and avoid the limitations of previously published research. 
Another study on a relatively small sample of type 1 diabetic patients was done by Malerbi et al. [29]. They found that microalbuminuria was associated with increased choroidal thickness in type 1 diabetes mellitus without diabetic retinopathy. This difference between type 1 and type $2 \mathrm{DM}$ is not well understood however, it could be related to the different age groups included in the studies, difference in disease duration, or could be related to the insulin resistance encountered in type 2 but not in type 1. Further longitudinal comparative studies are needed to clarify these differences.

In our study, CT in the 9 ETDRS sectors in diabetic patients with microalbuminuria showed no significant correlation with age, duration of DM, HbA1c, RBS, IOP, SE, AL, serum creatine, or eGFR. Similarly, Abadia et al. did not show any statistically significant relationship between HbA1c or the duration of diabetes and CT [30].

Choroidal thickness showed a negative correlation with UAER. This agrees with Farias et al. and Kocasarac et al. who found a significant negative correlation between proteinuria and $\mathrm{CT}$ in diabetic patients with nephropathy $[19,28]$. On the contrary, Garrido-Hermosilla et al. [31] found a significant positive correlation between $\mathrm{CT}$ and albuminuria in their study in which patients with clinically evident DR were included.

Aiming to understand the effect of different variables on $\mathrm{CT}$, we performed a multi-regression analysis, which showed that UAER is an important determinant of SFCT in microalbuminuric patients.

Variability in the results of the published studies highlights the possibility of the involvement of variable pathophysiological mechanisms. The increase in CT noticed in different studies was suggested to be a result of increased release of vascular endothelial growth factors (VEGF) or other cytokines, which mediate choroidal vasodilation and increased choroidal blood flow. Consequently, these changes may lead to an increase in the choroidal vascular layer thickness or increased vascular permeability with the consequent choroidal swelling [15, 32].

It has also been noted in several articles that the increased dropout of choroidal vessels may explain choroidal thinning, loss of choroidal capillaries, increased vascular resistance, and decreased choroidal flow in the foveal region. With the aid of Doppler flowmetry, choroidal blood flow and volume were found to be reduced in the foveal region in diabetic patients, including those without retinopathy [33, 34, 28, 29].

Kocasarac et al. [19] suggested that DM could affect $\mathrm{CT}$ through various mechanisms, such as autonomic dysfunction and microvascular damage. It may increase or decrease $\mathrm{CT}$ according to the most influential pathological effect. This vascular involvement has been supported by Sousa et al. [35] who demonstrated an early impairment of the physiological retinal vascular response in patients with type $1 \mathrm{DM}$ without clinical diabetic retinopathy.

In our study, although statistical analysis yielded significant results, however, we still believe that the results cannot be generalized. Owing to the controversial results in the literature, including our study, multicenter studies utilizing different designs and follow-up periods may provide more conclusive and consistent results. It remains unclear whether diabetic choroidopathy is a predicting, modulating, or causative factor of DR.

The current study is limited by the relatively small sample size, lack of follow-up, and the manual outline of the sclerochoroidal junction. In addition to being done in a single center with inclusion of patients from same ethnicity.

\section{Conclusions}

Decreased CT was significantly correlated with UAER in diabetic patients without retinopathy and otherwise normal kidney functions. This decrease in thickness might be a predictor of DR. Further longitudinal studies are needed for a definite conclusion.

\section{Acknowledgements}

We would like to thank Writefull for English language editing.

\section{Authors' contributions}

DMA and AAE-S shared in writing the first draft of this manuscript and in the statistical analysis. RHAA and MIS revised and edited the final version of this work. All authors shared in idea conceptualization and data collection. All authors read and approved the final manuscript.

\section{Funding}

Not applicable.

\section{Availability of data and materials}

Data supporting the results reported in the article can be accessed after communication with the corresponding author.

\section{Declarations}

Ethics approval and consent to participate

The study protocol was approved by the Research Ethics committee of the Faculty of Medicine, Ain Shams University. All participants provided written informed consent

\section{Consent for publication}

All participants provided written informed consent.

Competing interests

The authors declare that they have no competing interests.

Received: 20 May 2021 Accepted: 3 October 2021

Published online: 16 October 2021

\section{References}

1. Saeedi P, Petersohn I, Salpea P, Malanda B, Karuranga S, Unwin N, Colagiuri S, Guariguata L, Motala AA, Ogurtsova K, et al. Global and regional diabetes prevalence estimates for 2019 and projections for 2030 and 2045 
results from the International Diabetes Federation Diabetes Atlas, 9th edition. Diabetes Res Clin Pract. 2019;157:107843.

2. Chatterjee S, Khunti K, Davies MJ. Type 2 diabetes. Lancet. 2017;389(10085):2239-51

3. Yau JW, Rogers SL, Kawasaki R, Lamoureux EL, Kowalski JW, BekT, Chen SJ, Dekker JM, Fletcher A, Grauslund J, Haffner S, et al. Global prevalence and major risk factors of diabetic retinopathy. Diabetes Care. 2012;35(3):556-64.

4. Kashim RM, Newton P, Ojo O. Diabetic retinopathy screening: a systematic review on patients' non-attendance. Int J Environ Res Public Health. 2018. https://doi.org/10.3390/ijerph15010157.

5. Haider S, Sadiq SN, Moore D, Price MJ, Nirantharakumar K. Prognostic prediction models for diabetic retinopathy progression: a systematic review. Eye. 2019;33(5):702-13.

6. Naidoo DP. The link between microalbuminuria, endothelial dysfunction and cardiovascular disease in diabetes. Cardiovasc J S Afr. 2002;13(4):194-9.

7. Lee ES, Tang WE. The prevalence of albuminuria among diabetic patients in a primary care setting in Singapore. Singap Med J. 2015;56(12):681-6.

8. Hidayat AA, Fine BS. Diabetic choroidopathy: light and electron microscopic observations of seven cases. Ophthalmology. 1985;92(4):512-22.

9. Fryczkowski AW, Sato SEHB. Changes in the diabetic choroidal vasculature: scanning electron microscopy findings. Ann Ophthalmol. 1988:20(8):299-305.

10. Fryczkowski AW, Hodes BL, Walker J. Diabetic choroidal and iris vasculature scanning electron microscopy findings. Int Ophthalmol. 1989;13(4):269-79.

11. Fukushima I, McLeod DS, Lutty GA. Intrachoroidal microvascular abnormality: a previously unrecognized form of choroidal neovascularization. Am J Ophthalmol. 1997;124(4):473-87.

12. Singh SR, Vupparaboina KK, Goud A, Dansingani KK, Chhablani J. Choroidal imaging biomarkers. Surv Ophthalmol. 2019;64(3):312-33.

13. Querques G, Lattanzio R, Querques L, Del Turco C, Forte R, Pierro L, Souied EH, Bandello F, et al. Enhanced depth imaging optical coherence tomography in type 2 diabetes. Invest Ophthalmol Vis Sci. 2012;53(10):6017-24.

14. Esmaeelpour M, Považay B, Hermann B, et al. Mapping choroidal and retinal thickness variation in type 2 diabetes using three-dimensional 1060-nm optical coherence tomography. Invest Ophthalmol Vis Sci. 2011;52(8):5311-6.

15. Xu J, Xu L, Du KF, Shao L, Chen CX, Zhou JQ, Wang YX, You QS, Jonas JB, Wei WB, et al. Subfoveal choroidal thickness in diabetes and diabetic retinopathy. Ophthalmology. 2013;120(10):2023-8.

16. Tavares Ferreira J, Vicente A, Proença R, Santos BO, Cunha JP, Alves M, Papoila AL, Abegão Pinto L, et al. Choroidal thickness in diabetic patients without diabetic retinopathy. Retina. 2018;38(4):795-804.

17. Endo H, Kase S, Saito M, Yokoi M, Takahashi M, Ishida S, Kase M. Choroidal thickness in diabetic patients without diabetic retinopathy: a meta-analysis. Am J Ophthalmol. 2020;218:68-77.

18. Oliveira-Ferreira C, Leuzinger-Dias M, Tavares-Ferreira J, Falcão-Reis F, Rocha-Sousa A. Choroidal thickness and urinary albumin excretion in type 2 diabetic patients without retinopathy. J Ophthalmol. 2020. https:// doi.org/10.1155/2020/3648941.

19. Kocasarac C, Yigit Y, Sengul E, Sakalar YB. Choroidal thickness alterations in diabetic nephropathy patients with early or no diabetic retinopathy. Int Ophthalmol. 2018;38(2):721-6.

20. Flores-Moreno I, Lugo F, Duker JS, Ruiz-Moreno JM. The relationship between axial length and choroidal thickness in eyes with high myopia. Am J Ophthalmol. 2013;155(2):314-319.e1.
21. Molitch ME, DeFronzo RA, Franz MJ, Keane WF, Mogensen CE, Parving HH, Steffes MW, American Diabetes Association. Nephropathy in diabetes. Diabetes Care. 2004;27(Suppl 1):S79-83.

22. Levey AS, Bosch JP, Lewis JB, Greene T, Rogers N, Roth D. A more accurate method to estimate glomerular filtration rate from serum creatinine: a new prediction equation. Modification of Diet in Renal Disease Study Group. Ann Intern Med. 1999;130(6):461-70.

23. Tan CS, Ouyang Y, Ruiz H, Sadda SR. Diurnal variation of choroidal thickness in normal, healthy subjects measured by spectral domain optical coherence tomography. Invest Ophthalmol Vis Sci. 2012;53(1):261-6.

24. Adhi M, Liu JJ, Qavi AH, et al. Choroidal analysis in healthy eyes using swept-source optical coherence tomography compared to spectral domain optical coherence tomography. Am J Ophthalmol. 2014;157(6):1272-1281.e1.

25. Wei WB, Xu L, Jonas JB, Shao L, Du KF, Wang S, Chen CX, Xu J, Wang YX, Zhou JQ, You QS. Subfoveal choroidal thickness: the Beijing Eye Study. Ophthalmology. 2013;120(1):175-80.

26. Rani PK, Raman R, Gupta A, Pal SS, Kulothungan V, Sharma T. Albuminuria and diabetic retinopathy in type 2 diabetes mellitus sankara nethralaya diabetic retinopathy epidemiology and molecular genetic study (SNDREAMS, report 12). Diabetol Metab Syndr. 2011;3(1):9.

27. Persson F, Rossing P. Diagnosis of diabetic kidney disease: state of the art and future perspective. Kidney Int Suppl. 2018;8(1):2-7.

28. Farias LB, Lavinsky D, Benfica CZ, da Silva MO, Lavisnky J, Canani LH. Changes in choroidal thickness and volume are related to urinary albumin excretion in type 2 diabetic patients without retinopathy. Clin Ophthalmol. 2018;12:1405-11.

29. Malerbi FK, Regatieri CV, de Sa JR, Morales PH, Farah ME, Dib SA. Microalbuminuria is associated with increased choroidal thickness in type 1 diabetes mellitus patients without diabetic retinopathy. Acta Ophthalmol. 2018:96(1):e95-7.

30. Abadia B, Suñen I, Calvo P, Bartol F, Verdes G, Ferreras A. Choroidal thickness measured using swept-source optical coherence tomography is reduced in patients with type 2 diabetes. PLoS ONE. 2018;13(2):1-11.

31. Garrido-Hermosilla AM, Méndez-Muros M, Gutiérrez-Sánchez E, MoralesPortillo C, Díaz-Granda MJ, Esteban-González E, Relimpio-López I, Martínez-Brocca MA, Rodríguez-de-la-Rúa-Franch E. Renal function and choroidal thickness using swept-source optical coherence tomography in diabetic patients. Int J Ophthalmol. 2019;12(6):985-9.

32. Kim JT, Lee DH, Joe SG, Kim J-G, Yoon YH. Changes in choroidal thickness in relation to the severity of retinopathy and macular edema in type 2 diabetic patients. Invest Ophthalmol Vis Sci. 2013;54(5):3378-84.

33. Nagaoka T, Kitaya N, Sugawara R, Yokota H, Mori F, Hikichi T, Fujio N, Yoshida A. Alteration of choroidal circulation in the foveal region in patients with type 2 diabetes. Br J Ophthalmol. 2004;88(8):1060-3.

34. Schocket LS, Brucker AJ, Niknam RM, Grunwald JE, DuPont J, Brucker AJ. Foveolar choroidal hemodynamics in proliferative diabetic retinopathy. Int Ophthalmol. 2004;25(2):89-94.

35. Sousa DC, Leal I, Moreira S, do Vale S, Silva-Herdade AS, Aguiar P, Dionísio P, Abegão Pinto L, Castanho MARB, Marques-Neves C. Retinal vascular reactivity in type 1 diabetes patients without retinopathy using optical coherence tomography angiography. Invest Ophthalmol Vis Sci. 2020;61(6):49.

\section{Publisher's Note}

Springer Nature remains neutral with regard to jurisdictional claims in published maps and institutional affiliations. 